\title{
What Influences Online Coupon Sales in Chinese Catering Industry? ----Evidence from Empirical Study with Micro-data in Chinese Catering Industry
}

\author{
Zhe $\mathrm{Li}^{1, \mathrm{a}}$ \\ ${ }^{1}$ School of Finance, Renmin University of China, Beijing 100872, China; \\ a Lizhe3020@126.com
}

\begin{abstract}
Keywords: online coupon, sales, restaurant, quantity of commentary, customer, discount
\end{abstract}
\begin{abstract}
Online coupons are digital coupons that people could purchase at a lower price than its face value. The use of online coupons to attract consumers is very popular among restaurants. This research is to find out the influential factors of the coupon sales. Fourteen factors are chosen from three perspectives - restaurant characteristics, coupon characteristics, and customer characteristics. I propose a model of restaurant coupon sales that contains data of real customer behavior. Five factors are found to reduce the coupon sales as they increase. The factors include the price of the coupon, the discount offered by the coupon, the coupon's issuing duration, the occidental restaurant (one restaurant type) and service level. The other five factors increase the coupon sales as they increase. The factors include the quantity of the commentary, the location of the restaurant, the quantity of the restaurant's branch chain stores, the Chinese restaurant (one restaurant type), the Korean restaurant (one restaurant type), the Japanese restaurant (one restaurant type), the average consumption in the restaurant, the dish quality level and the environment level of the restaurant. The extended model also provides insights into the effects of the online commentary quantity of the restaurants on other factors and the coupon sales. This paper helps people know better about customer behavior and helps restaurants develop more effective coupon promotion strategies.
\end{abstract}

\section{Introduction}

Now electronic commerce in China is in its golden age. In 2016, the e-commerce transactions of China reached 26.1 trillion RMB, a transaction volume that is 2.5 times of the amount in 2013, with an average annual growth of $36.4 \%$. With the e-commerce's fast developing, catering industry, express industry, packaging services and many other industries grow rapidly. Simultaneously, there is far more data online and people start to analyze the big data, as well as the academia do research with the data. The data online has quite a large amount and it is the real reflection of consumer behavior from the most microcosmic perspective.

In the catering industry, not only large numbers of restaurants are opened, but also the form people run a restaurant varies with the time. The online meal ordering and delivery system becomes nearly perfect. Many on-line platforms are set up to share information and performance of the restaurants. The restaurants make different strategies to confront competition, like creating a special interesting theme for the restaurant or providing online coupons, which are also called group-buying coupons (groupons). Online coupons are easily acquired digital coupons and people could pay less money to exchange one worth more. Now online coupon is a general strategy of sales promotion in China, no matter the scale of the restaurant is large or small. As the new kind of coupon becoming more popular in business, more studies are launched to find the influences and the determinants of the sale of online coupons.

At first, scholars studies the group buying theoretically as this kind of business pullulates. One paper sets Fantuan as an example to analysis the reasons of their success of groupon and lists several resource superiorities of Fantuan. [1] Some studies concluded the characters, challenges and the problem of standardized management of online group buying market as groupon penetration reaches a new height. $[11 ; 12 ; 2]$

Previous studies examine the traditional and digital coupons' effect on customers' psychology. 
For instance, different kinds of discount price announcement have different effect on customer's psychology. In a situation where a higher discount rate is given, people would get a decline in their quality perception of the product. [10] And for hedonic customers and utilitarian customers, their different response to a digital coupon relies on their purchasing motivation and the type of benefit the product could provide. Utilitarian customers would have a stronger response to discount of utilitarian products. [5] Similar conclusions are also be proved under impression management. People pursue positive feelings through the control of self-perceptions. So when certain impression management goal is achieved, such as leaving an impression of being smart in individualists' opinion, more coupons will be used. [6]

Furthermore, there are some previous studies focusing on coupons in one certain industry, like coupons from restaurants, while most of them examine one factor's influence on the sales of the coupons, such like discount announcement, service quality and word-of-mouth. People have higher purchasing intention when high discount is in a percentage discount format than in a absolute discount format. The higher service level of the transaction website and the restaurant of the online coupon always bring higher sales of online coupon, but the environment of the restaurant have no obvious relation with the coupon sales. [7] The word-of-mouth have positive relevance with the sales of online coupon and more online comments represent higher credibility of the comments. [3; $8 ; 4]$

The customer psychology has been studied in many angles while few study tries to examine different factors' influence on coupon sales at the same time. This paper focuses on the restaurant coupons and tries to find influential objective factors and to what degree they could affect the coupon sale. Especially, this study chooses data from restaurants in one region, Beijing, to eliminate effects of irrelevant variables. Some studies choose restaurants from different cities. [9] However, people from different regions may have different ways to give feedback about their dining experience, which could result in unwanted effects. In this paper, I would use correlation analysis, regression analysis and model modification to determine the factors influencing online coupon sale.

This paper tries to find out which factors would influence the sale volume of online coupon. From the estimated model, there are 6 factors swaying online coupon's sale- the price of the coupon, per capita consumption, the quantity of the commentary, the discount, quantity of branch chain store and geographical location. Among these factors, quantity of the online commentary matters most, which not only influences the coupon sales but also have effects on other factors. The duration of the issuing, restaurant's quality and the type of the dishes show no effect to the sale volume. So this paper focuses more on the study of effects brought by quantity of the commentary.

My research selects data from a popular groupon website in China, Dazhong, collecting restaurant information and customer commentary in every city of China. So firstly, the data is quite large and diverse. All the subjective information of a restaurant is from customers who have dined in that restaurant. Secondly, there has no similar existed database, which collects such subjective information like I did. Thirdly, I choose only one city to study so that the result of the model is focused on the characters of the coupons and the restaurants, but not influences caused by choosing different cities. So my research could fill in some of the blank in current studies.

The whole paper is written as 4 parts. For the rest parts, the first part illustrates methodology, including the dataset and the model. The second part is results of the model and analysis. And the third part is conclusions, including limitations of the paper and further work.

\section{Research Methodology}

Sample and Data Collection. I search all the data from a well known website in China, http://t.dianping.com/, which provides restaurant information, customer evaluations, customer reviews, and online coupons for more than 10,000 restaurants at various quality levels in Beijing. The website is free to everybody and among the mobile phone users who can surf the internet by their phone, $85 \%$ of them have looked through this website. It's widely recognized and used.

I didn't collect each restaurant's information. I select them by stratified sampling. Firstly, I order the restaurant from the highest coupon price to the lowest. Then I choose the first one on each page. There show 133 pages, so I collect information of 16 variables from 133 restaurants. And in the final 
model, I omit several outliers because the data is fragmentary data. There remain 128 observations.

The sale volume of the online coupons is the explained variable, and I select explanatory variables from three perspectives: restaurant characteristics, coupon characteristics and customer characteristics. For the restaurant characteristics, I select the type of the restaurant, the location of the restaurant and the quantity of the branch chain stores of the restaurant, to find the effects of different food type, location and scale of operation. For coupon characteristics, the quantity of sold coupon, the purchasing price, the discount and the release period are selected as variables. For customer characteristics, I choose four kinds of scores given by customers to mark the quality of the restaurant and the quantity of commentary posted online as explanatory variables. The scores are selected as average scores to eliminate personal prejudice against the restaurant. Here is the variable definition.

Table1. Variables Definition

\begin{tabular}{c|l|l}
\hline Variables & Definition & Notes for dummy variables \\
\hline Explained Variable: & \\
\hline $\mathrm{S}$ & $\begin{array}{l}\text { The sale volume of } \\
\text { online coupon of } \\
\text { restaurants }\end{array}$ & \\
\hline
\end{tabular}

\begin{tabular}{c|l|}
\hline Explanatory Variable: \\
\hline \multicolumn{2}{c|}{ Restaurant characteristics } \\
\hline $\mathrm{T}_{\mathrm{C}}$ & Chinese restaurant \\
$\mathrm{T}_{\mathrm{K}}$ & Korean restaurant \\
$\mathrm{T}_{\mathrm{J}}$ & Japanese restaurant \\
$\mathrm{T}_{\mathrm{O}}$ & Occidental restaurant \\
$\mathrm{L}$ & The location of the \\
& restaurant is in \\
$\mathrm{B}$ & bustling area or not \\
& The quantity of the \\
& branch chain stores of \\
& the restaurant
\end{tabular}

If it is a Chinese restaurant, $\mathrm{T}_{\mathrm{C}}=1 ;$ else, $\mathrm{T}_{\mathrm{C}}=0$

If it is a Korean restaurant, $\mathrm{T}_{\mathrm{K}}=1$; else, $\mathrm{T}_{\mathrm{K}}=0$

If it is a Japanese restaurant, $T_{\mathrm{J}}=1$; else, $\mathrm{T}_{\mathrm{J}}=0$

If it is an Occidental restaurant, $\mathrm{T}_{\mathrm{O}}=1$; else, $\mathrm{T}_{\mathrm{O}}=0$

If the restaurant is in bustling area, $\mathrm{L}=1$; else, $\mathrm{L}=0$

If the restaurant only has 1 store, $\mathrm{B}_{1}=1$; else, $\mathrm{B}_{1}=0$

If the restaurant has 2 branch chain stores, $\mathrm{B}_{2}=1$; else, $\mathrm{B}_{2}=0$

If the restaurant has 2-10 branch chain stores, $\mathrm{B}_{3}=1$; else, $\mathrm{B}_{3}=0$

If the restaurant has more than 10 branch chain stores, $B_{4}=1$; else, $B_{4}=0$

\section{Coupon characteristics}

\begin{tabular}{l|l}
$\mathrm{P}$ & The price to buy the
\end{tabular} coupon, but not the nominal value of the coupon

M The percentage of the original price the restaurants offer

If the restaurant offers a $0 \%-10 \%$ discount, $M_{1}=1$; else, $M_{1}=0$ If the restaurant offers a $10 \%-15 \%$ discount, $\mathrm{M}_{2}=1$; else, $\mathrm{M}_{2}=0$ If the restaurant offers a $15 \%-20 \%$ discount, $\mathrm{M}_{3}=1$; else, $\mathrm{M}_{3}=0$ If the restaurant offers a $20 \%-30 \%$ discount, $\mathrm{M}_{4}=1$; else, $\mathrm{M}_{4}=0$ If the restaurant offers a discount more than $30 \%, \mathrm{M}_{5}=1$; else, $\mathrm{M}_{5}=0$

D Quantity of months If the coupon has posted for less than one month, $\mathrm{D}_{1}=1 ;$ else, $\mathrm{D}_{1}=0$ the coupons have If the coupon has posted for 2-11 months, $D_{2}=1$; else, $D_{2}=0$ been provided

If the coupon has posted for 12-17 months, $D_{3}=1$; else, $D_{3}=0$ If the coupon has posted for more than 18 months, $D_{4}=1 ;$ else, $D_{4}=0$

\begin{tabular}{c|l|}
\hline Customer characteristics \\
\hline $\mathrm{C}_{\mathrm{spt}}$ & $\begin{array}{l}\text { The amount of RMB } \\
\text { on average each } \\
\text { person consume in } \\
\text { the restaurant } \\
\text { The score the } \\
\text { customers give to } \\
\text { mark the environment } \\
\text { of the restaurant } \\
\text { The score the } \\
\text { customers give to } \\
\text { mark the quality of }\end{array}$ \\
$\mathrm{S}_{\text {score }}$
\end{tabular}




\begin{tabular}{c|l|l}
$\mathrm{T}_{\mathrm{score}}$ & $\begin{array}{l}\text { the service in the } \\
\text { restaurant } \\
\text { The score the } \\
\text { customers give to } \\
\text { mark the taste of the } \\
\text { dishes } \\
\text { Quantity of the } \\
\text { commentary }\end{array}$ & $\begin{array}{l}\text { If the restaurant has } 0-130 \text { reviews, } Q_{\mathrm{Cl}}=1 ; \text { else, } \mathrm{Q}_{\mathrm{Cl}}=0 \\
\text { If the restaurant has } 130-275 \text { reviews, } \mathrm{Q}_{\mathrm{C} 2}=1 ; \text { else, } \mathrm{Q}_{\mathrm{C} 2}=0 \\
\text { If the restaurant has } 275-875 \text { reviews, } \mathrm{Q}_{\mathrm{C} 3}=1 ; \text { else, } \mathrm{Q}_{\mathrm{C} 3}=0 \\
\text { If the restaurant has more than } 875 \text { reviews, } \mathrm{Q}_{\mathrm{C} 4}=1 ; \text { else, } \mathrm{Q}_{\mathrm{C} 4}=0\end{array}$ \\
\hline
\end{tabular}

Here is the description of the variables.

Table 2 The Descriptive Statistics of Variables

\begin{tabular}{|c|c|c|c|c|c|}
\hline Variables & Mean & Maximum & Minimum & $\begin{array}{c}\text { Standard } \\
\text { Deviation }\end{array}$ & Variance \\
\hline $\mathrm{T}_{\mathrm{C}}$ & 0.4812 & 1 & 0 & 0.5015 & 0.2515 \\
\hline $\mathrm{T}_{\mathrm{K}}$ & 0.0752 & 1 & 0 & 0.2647 & 0.0701 \\
\hline $\mathrm{T}_{\mathrm{J}}$ & 0.1729 & 1 & 0 & 0.3796 & 0.1441 \\
\hline $\mathrm{T}_{\mathrm{O}}$ & 0.1429 & 1 & 0 & 0.3513 & 0.1234 \\
\hline $\mathrm{L}$ & 0.5338 & 1 & 0 & 0.5007 & 0.2507 \\
\hline B & 5.5714 & 82 & 1 & 10.9263 & 119.3832 \\
\hline $\mathrm{B}_{1}$ & 0.4211 & 1 & 0 & 0.4956 & 0.2456 \\
\hline $\mathrm{B}_{2}$ & 0.2481 & 1 & 0 & 0.4336 & 0.1880 \\
\hline $\mathrm{B}_{3}$ & 0.1880 & 1 & 0 & 0.3922 & 0.1538 \\
\hline $\mathrm{B}_{4}$ & 0.1429 & 1 & 0 & 0.3513 & 0.1234 \\
\hline $\mathrm{P}$ & 168.7331 & 850 & 25 & 120.55 & 14532.06 \\
\hline $\mathrm{M}$ & 0.1820 & 0.02 & 0.8 & 0.1270 & 0.0161 \\
\hline $\mathrm{M}_{1}$ & 0.1128 & 1 & 0 & 0.3175 & 0.1008 \\
\hline $\mathrm{M}_{2}$ & 0.3609 & 1 & 0 & 0.4821 & 0.2324 \\
\hline $\mathrm{M}_{3}$ & 0.2180 & 1 & 0 & 0.4145 & 0.1718 \\
\hline $\mathrm{M}_{4}$ & 0.1654 & 1 & 0 & 0.3730 & 0.1391 \\
\hline $\mathrm{M}_{5}$ & 0.1429 & 1 & 0 & 0.3513 & 0.1234 \\
\hline $\mathrm{D}$ & 8.2707 & 37 & 1 & 8.0905 & 65.4565 \\
\hline $\mathrm{D}_{1}$ & 0.3910 & 1 & 0 & 0.4898 & 0.2399 \\
\hline $\mathrm{D}_{2}$ & 0.2481 & 1 & 0 & 0.4336 & 0.1880 \\
\hline $\mathrm{D}_{3}$ & 0.2030 & 1 & 0 & 0.4038 & 0.1630 \\
\hline $\mathrm{D}_{4}$ & 0.1579 & 1 & 0 & 0.3660 & 0.1340 \\
\hline $\mathrm{C}_{\mathrm{spt}}$ & 112.12 & 398 & 23 & 62.3222 & 3884.05 \\
\hline$E_{\text {score }}$ & 8.9120 & 9.3 & 7 & 0.4099 & 0.1680 \\
\hline $\mathrm{S}_{\text {score }}$ & 8.8308 & 9.3 & 7.1 & 0.4284 & 0.1835 \\
\hline $\mathrm{T}_{\text {score }}$ & 8.8737 & 9.3 & 7.3 & 0.3748 & 0.1404 \\
\hline $\mathrm{Q}_{\mathrm{C}}$ & 2965.96 & 80133 & 11 & 10289.63 & 105876485.54 \\
\hline $\mathrm{Q}_{\mathrm{C} 1}$ & 0.2481 & 1 & 0 & 0.4336 & 0.1880 \\
\hline $\mathrm{Q}_{\mathrm{C} 2}$ & 0.2481 & 1 & 0 & 0.4336 & 0.1880 \\
\hline $\mathrm{Q}_{\mathrm{C} 3}$ & 0.2406 & 1 & 0 & 0.4291 & 0.1841 \\
\hline $\mathrm{Q}_{\mathrm{C} 4}$ & 0.2632 & 1 & 0 & 0.4420 & 0.1954 \\
\hline
\end{tabular}

For restaurant characteristics, we could see that more than $48 \%$ of the restaurants are Chinese restaurants, while Korean, Japanese, Occidental and other kinds of restaurants each occupy less than $20 \%$. The geographical distribution has no obvious feature. And most of the investigated restaurants have no other branch chain stores. Besides, Half of the restaurants are located in bustling area and half are not. For coupon characteristics, we could see that most restaurants offer $10 \%-20 \%$ discount on their coupons and the period of validity of more than $60 \%$ of the coupons is less than 10 months. For customer characteristics, the scores customers give to mark the quality of the restaurants are generally high and dense, and the quantity of commentary posted online are nearly uniformly 
distributed. The average consumption per capita varies from $23 \mathrm{RMB}$ to $398 \mathrm{RMB}$, with a large range. $\ln S$

\section{The OLS Model}

$$
\begin{aligned}
& =\beta 0+\beta 1 \mathrm{P}+\Sigma \beta 2 \mathrm{iQCi}+\beta 3 \mathrm{jBj}+\Sigma \beta 4 \mathrm{kDk}+\beta 5 \mathrm{Cspt}+\beta 6 \mathrm{Escore}+\beta 7 \mathrm{Sscore}+\beta 8 \mathrm{~T} \\
& \text { score }+\Sigma \beta 9 \mathrm{xTx}+\beta 10 \mathrm{~L}+\Sigma \beta 11 \mathrm{~m} \mathrm{Mm}+\varepsilon
\end{aligned}
$$

$$
\begin{aligned}
& \mathrm{i}, \mathrm{j}, \mathrm{k}=1,3,4 \\
& \mathrm{~m}=1,3,4,5 \\
& \mathrm{x}=\mathrm{C}, \mathrm{K}, \mathrm{J}, \mathrm{O}
\end{aligned}
$$

The model used in this research is OLS regression. This regression model is simple and direct, and easy to conduct tests. OLS regression could accurately measure the correlation between the factors and the model's fitting degree. It could also give a single and confirmed result provided that the data input is fixed.

The presence of endogeneity may bias the parameter estimates. However, the endogenous problem in this model is not significant. As the restaurant rarely adjust their coupon characteristics according to the coupon sales, coupon's sales volume has little adverse effect to coupon's characteristics. Besides, the coupon characteristics and customer characteristics has little correlation. Although the

\begin{tabular}{|c|c|c|c|}
\hline & $\begin{array}{l}\text { (1) } \\
\text { Qc }\end{array}$ & $\begin{array}{c}(2) \\
\text { noQc }\end{array}$ & $\begin{array}{c}(3) \\
\text { banchmark }\end{array}$ \\
\hline Qc & $\begin{array}{l}0.955^{* * *} \\
(0.026)\end{array}$ & & $\begin{array}{l}0.893 * * * \\
(0.026)\end{array}$ \\
\hline $\mathrm{L}$ & & $\begin{array}{c}1.098 \\
(0.176)\end{array}$ & $\begin{array}{r}0.079 \\
(0.073)\end{array}$ \\
\hline B & & $\begin{array}{l}0.485^{* * * *} \\
(0.092)\end{array}$ & $\begin{array}{l}0.113^{* * *} \\
(0.036)\end{array}$ \\
\hline Tc & & $\begin{array}{l}-0.379 \\
(0.267)\end{array}$ & $\begin{array}{r}0.080 \\
(0.098)\end{array}$ \\
\hline Tk & & $\begin{array}{c}0.251 \\
(0.393)\end{array}$ & $\begin{array}{c}0.082 \\
(0.144)\end{array}$ \\
\hline $\mathrm{Tj}$ & & $\begin{array}{r}0.169 \\
(0.313)\end{array}$ & $\begin{array}{r}0.106 \\
(0.115)\end{array}$ \\
\hline To & & $\begin{array}{l}-0.092 \\
(0.313)\end{array}$ & $\begin{array}{l}-0.168 \\
(0.115)\end{array}$ \\
\hline $\mathrm{P}$ & & $\begin{array}{l}-0.588 * * * \\
(0.156)\end{array}$ & $\begin{array}{l}-0.514 * * * \\
(0.057)\end{array}$ \\
\hline M & & $\begin{array}{l}-0.661 \\
(0.662)\end{array}$ & $\begin{array}{l}-0.825^{* * *} \\
(0.248)\end{array}$ \\
\hline D & & $\begin{array}{r}0.024 \\
(0.011)\end{array}$ & $\begin{array}{l}-0.004 \\
(0.004)\end{array}$ \\
\hline Cspt & & $\begin{array}{l}0.511^{* *} \\
(0.225)\end{array}$ & $\begin{array}{l}0.840^{* * * *} \\
(0.082)\end{array}$ \\
\hline Tscore & & $\begin{array}{l}0.895 * * \\
(0.362)\end{array}$ & $\begin{array}{r}0.053 \\
(0.133)\end{array}$ \\
\hline Escore & & $\begin{array}{c}0.015 \\
(0.426)\end{array}$ & $\begin{array}{r}0.106 \\
(0.157)\end{array}$ \\
\hline Sscore & & $\begin{array}{l}-0.465 \\
(0.501)\end{array}$ & $\begin{array}{l}-0.220 \\
(0.182)\end{array}$ \\
\hline _cons & $\begin{array}{l}2.421 * * * \\
(0.161)\end{array}$ & $\begin{array}{c}3.236 \\
(2.259)\end{array}$ & $\begin{array}{l}1.985^{* * *} \\
(0.820)\end{array}$ \\
\hline $\mathrm{N}$ & 133 & 133 & 133 \\
\hline
\end{tabular}
set factors of the coupons may influence the customers' behavior characteristics, the coupon sales' influence to individual customer characteristics is negligible.

\section{Result and discussion}

Table 3 Benchmark model 
Standard errors in parentheses

$* \mathrm{p}<0.1, * * \mathrm{p}<0.05, * * * \mathrm{p}<0.01$

For restaurant characteristics, the location of the restaurants has positive relationship with coupon sales volume. The restaurants locating in busy area sell more coupons than the restaurants locating in less busy area, while the significance of L is low. The customer base of the restaurants in busy area is larger. The quantity of the branch chain stores of the restaurant has positive relationship with coupon sales. The more branch chain stores the restaurant has, the more choices the customers have to use the coupons. The type of the restaurants shows little relationship with coupon sales. Customer cares little about the restaurant type when they buy the online coupons.

For coupon characteristics, the coupon price and the discount of the coupon have negative relationship with coupon sales. We could judge from common sense that people are more willing to buy a coupon if its price is lower. The higher discount the coupon offers, the fewer people buy the coupon. The discount offered by the coupons represents both the price of the dished and the quality of the dishes, but people are less sensitive to its price changing function than to its quality symbol function. People consider the probability of low dish quality very low if the restaurant provide high discount. For the issue time of online coupon, it has negative relation with the coupon sales, but its coefficient is close to zero and this factor has very low significance.

For customer characteristics, the average consumption in the restaurant and the quantity of commentary on the website have positive relationship with coupon sales volume. For restaurants with higher average consumption, people have more desire to reduce their expenditure. For restaurants with more online commentaries, people know more information about the restaurants and have higher reliability on the quality of the restaurants. The four kinds of scores of the restaurant seem to affect the coupon sales little. When customers make their purchase decision on the online coupons, they do not focus on the scores given by other customers. The scores have low validity.

As the absolute values of $\mathrm{S}$ (the sale volume of online coupon), QC (the quantity of the commentary of the restaurant), $\mathrm{P}$ (the price to buy the coupon), B (the quantity of the branch chain stores of the restaurant), and Cspt (the amount of RMB on average each person consume in the restaurant) are much bigger than the other variables, I put a log on these variables. It is found that the significance of Tscore (the score the customers give to mark the taste of the dishes) will decrease a lot if adding log on QC, which reveals that QC is the substitution variable of Tscore. The reason why the quantity of the commentary of the restaurant could represent the taste of the dishes in that restaurant may be the quantity of the commentary matters more for the customers. The commentary quantity ranges a lot and the scores of different restaurants are similar. For any restaurant, customers hardly give 1 or 2 points (Full points is 5). Most people give 4 or 5, so the difference among the scores cannot represent the wide difference among the taste of the dishes. So the validity of the scores is low.

In this regression, the variable $\mathrm{QC}$ is a key dependent variable, and several relative interaction terms are added to the regression to find further conclusions. 


\begin{tabular}{|c|c|c|c|c|}
\hline & $\begin{array}{l}\text { (1) } \\
\text { banckmark }\end{array}$ & $\begin{array}{l}\text { (2) } \\
\text { LQc }\end{array}$ & $\begin{array}{l}\text { (3) } \\
\mathrm{BQc}\end{array}$ & $\begin{array}{l}(4) \\
\text { MQc }\end{array}$ \\
\hline \multirow{2}{*}{$\mathrm{L}$} & 0.079 & 0.091 & 0.092 & $0.134^{*}$ \\
\hline & $(0.073)$ & $(0.073)$ & $(0.074)$ & $(0.072)$ \\
\hline \multirow[t]{2}{*}{ B } & $0.113 * * *$ & $0.103 * * *$ & $0.103 * * *$ & $0.085 * * *$ \\
\hline & $(0.036)$ & $(0.036)$ & $(0.037)$ & $(0.035)$ \\
\hline \multirow[t]{2}{*}{ Tc } & 0.080 & 0.055 & 0.061 & 0.013 \\
\hline & $(0.098)$ & $(0.099)$ & (0.099) & $(0.095)$ \\
\hline \multirow[t]{2}{*}{ Tk } & 0.082 & 0.093 & 0.092 & 0.083 \\
\hline & $(0.144)$ & $(0.144)$ & $(0.144)$ & $(0.138)$ \\
\hline \multirow[t]{2}{*}{$\mathrm{Tj}$} & 0.106 & 0.116 & 0.114 & 0.110 \\
\hline & $(0.115)$ & (0.114) & $(0.115)$ & $(0.110)$ \\
\hline \multirow[t]{2}{*}{ To } & -0.168 & -0.161 & -0.162 & -0.151 \\
\hline & $(0.115)$ & $(0.114)$ & $(0.115)$ & $(0.110)$ \\
\hline \multirow[t]{2}{*}{$\mathrm{P}$} & $-0.514 * * *$ & $-506 * * *$ & $-0.506 * * *$ & $-0.485 * * *$ \\
\hline & $(0.057)$ & $(0.057)$ & $(0.057)$ & $(0.055)$ \\
\hline \multirow[t]{2}{*}{ M } & $-0.825 * * *$ & $-0.779 * * *$ & $-0.792 * * *$ & $-0.889 * * *$ \\
\hline & $(0.248)$ & $(0.248)$ & $(0.248)$ & $(0.237)$ \\
\hline \multirow[t]{2}{*}{ D } & -0.004 & -0.004 & -0.004 & -0.003 \\
\hline & $(0.004)$ & $(0.004)$ & $(0.004)$ & $(0.004)$ \\
\hline \multirow[t]{2}{*}{ Cspt } & $0.840 * * *$ & $0.816^{* * *}$ & $0.818^{* * *}$ & $0.763 * * *$ \\
\hline & $(0.082)$ & $(0.083)$ & $(0.083)$ & $(0.081)$ \\
\hline \multirow[t]{2}{*}{ Qc } & $0.893 * * *$ & $0.869 * * *$ & $0.875 * * *$ & $0.820 * * *$ \\
\hline & $(0.026)$ & $(0.031)$ & $(0.030)$ & $(0.032)$ \\
\hline \multirow[t]{2}{*}{ Tscore } & 0.053 & 0.097 & 0.087 & 0.116 \\
\hline & (0.133) & $(0.136)$ & $(0.136)$ & $(0.129)$ \\
\hline \multirow[t]{2}{*}{ Escore } & 0.106 & 0.107 & 0.104 & 0.083 \\
\hline & $(0.157)$ & $(0.156)$ & $(0.156)$ & $(0.150)$ \\
\hline \multirow[t]{2}{*}{ Sscore } & -0.220 & -0.263 & -0.251 & -0.267 \\
\hline & $(0.182)$ & $(0.183)$ & $(0.183)$ & $(0.174)$ \\
\hline LQc & & $\begin{array}{l}-0.000 * \\
(0.000)\end{array}$ & & \\
\hline BQc & & & $\begin{array}{l}-0.000^{*} \\
(0.000)\end{array}$ & \\
\hline Mqc & & & & $\begin{array}{l}0.000 * * * \\
(0.000)\end{array}$ \\
\hline _cons & $\begin{array}{l}1.985^{* * * *} \\
(0.820)\end{array}$ & $\begin{array}{l}2.175^{* * * *} \\
(0.825)\end{array}$ & $\begin{array}{l}2.135^{* *} \\
(0.826)\end{array}$ & $\begin{array}{l}2.657 * * * \\
(0.805)\end{array}$ \\
\hline $\mathrm{N}$ & 133 & 133 & 133 & 133 \\
\hline
\end{tabular}

The interaction term of $\mathrm{L}$ (the location of the restaurant is in bustling area or not) and $\mathrm{Q}_{\mathrm{C}}$ is added into the regression. For the restaurants locating in busy area, more of their customers are passing-by customers. More people walk into these restaurants as these restaurants have better exposure. So the influence of online information on the coupon sales of restaurants locating in less busy area is greater, which explains the negative coefficient of the interaction term of $\mathrm{L}$ and $\mathrm{Q}_{\mathrm{C}}$.

The quantity of commentary's influence to S (coupon sale) is also proved to have relation with B (quantity of the branch chain stores of the restaurant). For restaurants that have big name and have many branch chain stores, there will be brand effect. People may choose to buy the coupon of these restaurants no matter what commentary they have. So the crowding out effect explains the negative coefficient of the interaction term of B and $\mathrm{Q}_{\mathrm{C}}$.

$\mathrm{Q}_{\mathrm{c}}$ 's influence to $\mathrm{S}$ has positive relation with $\mathrm{M}$ (the discount offered by the coupons), as the sign of the interaction term of $\mathrm{M}$ and $\mathrm{Q}_{\mathrm{C}}$ is positive. Compared with restaurants having low discount and fewer comments, restaurants with high discount and more comments are more likely to be chosen by the customer. The higher discount offered by the restaurant will reduce the customers' expectation on the dishes' taste and quality. Hence, M's negative influence on the coupon sales will reduce as the 
commentary quantity of the restaurant increases, which explains the negative coefficient of the interaction term of $\mathrm{M}$ and $\mathrm{Q}_{\mathrm{C}}$.

\section{Conclusion}

This paper studies the fourteen factors' influences on the restaurant coupon sales by empirical research. Some factors have negative influence on the coupon sales, including the price of the coupon, the discount offered by the coupon, the coupon's issuing duration, the occidental restaurant (restaurant type) and service level. The other factors have positive influence on the coupon sales, including the quantity of the commentary, the location of the restaurant, the quantity of the branch chain stores of the restaurant, the Chinese restaurant (restaurant type), the Korean restaurant (restaurant type), the Japanese restaurant (restaurant type), the average consumption in the restaurant, the dish quality level, the environment level of the restaurant. The study also studies several interaction terms of commentary quantity and shows the significant influence of commentary quantity on the restaurants. The commentary quantity has negative influence in the restaurant location's effect on the coupon sales, the branch store quantity's effect and the discount's effect. Besides, the commentary quantity could replace the score of the dishes. The scores may be subjective, but the quantity of commentary represents the quantity of people who have had meals in the restaurants. This factor is more objective and represents the general quality of the restaurants. The reasons why the scores have low validity need more research, which could also give people insights in how to develop a more effective scoring system.

\section{Reference}

[1] Chen, J. (2010). The success of Fantuan Website. China New Time, 2010(06), 76-78.

[2] Chen, Y. (2012). Analysis on the standardized management of the online group buying market. Electronic Commerce, DOI:10.13395/j.cnki.issn.1009-0061.2012.06.010

[3] Gao, J. (2012). Research on the negative online word-of-Mouth's influence on Group-buying intention. master thesis. Southwestern University of Finance and Economics. China.

[4] Han, J. (2016). A study of the relationship among online reviews, perceived risk, purchase intention based on catering network. master thesis. Xinjiang University of Finance and Economics.China.

[5] Khajezadeh, S., Oppewal, H., \& Tojib, D. (2014). Consumer responses to mobile coupons: The roles of shopping motivation and regulatory fit. Journal of Business Research, 67, 2447-2455.

[6] Kim, C.H. \& Yi, Y. (2016). The effects of impression management on coupon redemption across cultures. Psychology \& Marketing, 33(7), 573-583.

[7] Liu, J. (2013). The research of the relationship between online group buying service quality and customer behavior. master thesis. Nanjing Normal University. China.

[8] Lu, X., Ba, S., Huang, L., \& Feng, Y. (2013). Promotional marketing or world-of-mouth? Evidence from online restaurant reviews. Information Systems Research, 24, 596-612

[9] Sun, W. (2012). The research of the factors affecting online group-buying catering products turnover. master thesis. Southwest Jiaotong University. China.

[10]Brito, E.P.Z. \& Espartel, L.B. (2012). Influence of discount price announcements on consumer's behavior. Rae Revista De Administração De Empresas, 52(6), 657-671.

[11]Xu, L. (2011). Catering industry and group buying. Software Engineering, 2017(10), 37-39.

[12]Zhao, Y. (2011). Marketing mode combined with SNS brings great opportunity for the catering industry. China Computer \& Communication, 201106, 47-48. 